\title{
3'UTR Polymorphism of Thymidylate Synthase gene increased the risk of persistence of pre-neoplastic cervical lesions
}

Nayara Nascimento Toledo Silva ( $\square$ nayarants@gmail.com )

Universidade Federal de Ouro Preto https://orcid.org/0000-0002-0970-291X

\section{Ana Carolina Silva Santos}

Universidade Federal de Ouro Preto

\section{Verlândia Mendes Nogueira}

Centro Estadual de Atenção Especializada de Itabirito

Cláudia Martins Carneiro

Universidade Federal de Ouro Preto

Angelica Alves Lima

Universidade Federal de Ouro Preto

Research article

Keywords: Genetic polymorphisms, Thymidylate Synthase, TS3'UTR, pre-neoplastic cervical lesions, HPV

Posted Date: April 1st, 2020

DOI: https://doi.org/10.21203/rs.2.18713/v3

License: (c) (1) This work is licensed under a Creative Commons Attribution 4.0 International License. Read Full License

Version of Record: A version of this preprint was published at BMC Cancer on April 15th, 2020. See the published version at https://doi.org/10.1186/s12885-020-06811-7. 


\section{Abstract}

Background: Cervical cancer is caused by high-risk Human Papillomavirus (hr-HPV) infection associated with cofactors that has been analyzed as predictors of the remission or persistence of cytological abnormalities remission or persistence. These cofactors can be either environmental, epigenetic, or genetic. Polymorphism in genes of enzymes that act on one-carbon metabolism alter their activity and also may be associated with cervical carcinogenesis because they affect DNA synthesis and repair, and gene expression. Therefore, this study aimed to analyze the risk of persistence of pre-neoplastic cervical lesions according to genetic polymorphisms involved in one-carbon metabolism.

Methods: Our sample consisted of 106 women, divided into two groups - Remission ( $n=60)$, i.e., with the presence of pre-neoplastic lesions at first meeting (T1) and normal cytology after six months of follow-up (T2), and Persistence $(n=46)$, i.e., with the presence of pre-neoplastic lesions at T1 and T2. We obtained cervical samples for cytological analysis (T1 and T2), HPV detection (T1), and evaluation of polymorphism C667T of Methylenetetrahydrofolate Reductase (MTHFR C677T), A2756G of Methionine Synthase (MS A2756G), A66G of Methionine Synthase Reductase (MTRR A66G), double or triple 28 bp tandem repeat in 5'-untranslated enhanced region of Thymidylate Synthase (TSER), and 6 bp deletion at nucleotide1494 in TS 3'-untranslated region (TS3'UTR). To analyze all genetic polymorphisms simultaneously, we calculated the Genetic Risk Score (GRS).

Results: We observed no differences between the Remission and Persistence groups regarding the GRS. Also, there were no differences in the genotypic and allelic distribution of MTHFR C677T and MS A2756G polymorphisms. However, the risk of persistence was higher among women with the heterozygote genotype - ins/del [OR (IC95\%): $3.22(1.19-8.69), p=0.021]$, or the polymorphic genotype - del/del [OR (IC95\%): 6.50 (1.71 - 24.70), p=0.006] of TS3'UTR.

Conclusions: The presence of the TS3'UTR polymorphism increased the risk of persistence of cervical abnormalities. This genetic variant could be a potential marker of cervical carcinogenesis and therefore assist the follow-up of women with persistent pre-neoplastic cervical lesions.

\section{1) Background}

Persistent high-risk Human Papillomavirus (hr-HPV) infection is the main cause of cervical cancer. However, only $10 \%$ of the women infected by hr-HPV develop pre-neoplastic lesions and less than $1 \%$ progress to cervical cancer. Only approximately $30 \%$ of high-grade cervical lesions progress to uterine cervix cancer, and spontaneous regression occurs in $20-40 \%$ of the cases (1-4). Thus, the risk of cervical carcinogenesis depends on hr-HPV infection and host-dependent features $(5,6)$. Environmental, genetic, and epigenetic cofactors of cervical carcinogenesis has been analyzed as markers for diagnosis, prognosis, and for auxiliary the treatment of pre-neoplastic cervical lesions since they could be predictors of cytological abnormalities remission or persistence (7-10). 
Several genetic alterations characterize cervical cancer, such as genomic instability, chromosomal aberration, and the integration of the HPV DNA into the host genome $(4,7)$. These alterations may impact the risk of cervical carcinogenesis substantially. Polymorphism in the genes of enzymes that act on onecarbon metabolism alter their activity and may be associated with cervical carcinogenesis (11-13). Some of these enzymes are Methylenetetrahydrofolate Reductase (MTHFR), Methionine Synthase (MS), Methionine Synthase Reductase (MTRR), and Thymidylate Synthase (TS).

The MTHFR enzyme, whose gene is located on chromosome 1p36.3, is a flavoprotein that acts on folate metabolism and is essential for DNA integrity (14). MTHFR C677T polymorphism consists of the exchange of cytosine (C) for thymine $(T)$ at nucleotide 677 . Such polymorphism results in the substitution of Alanine for Valine, which leads to a decrease in MTHFR activity $(14,15)$. This Single Nucleotide Polymorphism (SNP) can change the susceptibility to carcinogenesis by modulating the availability of 5,10-methyleneTHF at different points in folate metabolism (16).

MS is a vitamin B12-dependent enzyme, essential to the maintenance of intracellular folate levels; it also catalyzes the methylation of homocysteine to methionine $(17,18)$. What causes the MS A2756G polymorphism is the exchange of adenine (A) for guanine $(G)$ at nucleotide 2756 - which results in the substitution of Aspartic Acid for Glycine, close to the binding domain of vitamin B12 $(19,20)$. Van Der Put et al. (1997) suggested that this SNP affects the secondary structure of MS and has functional consequences. A study has demonstrated the association between the polymorphic allele (G) of MS and the reduction of the number of hypermethylated $\mathrm{CpG}$ islands in tumor suppressor genes (21). Thus, MS A2756G may alter the activity of tumor suppressor genes, which would explain its association with the development of several types of tumors (22).

MTRR catalyzes the methylation of vitamin B12, which is a cofactor of MS enzyme (23). A66G polymorphism of MTRR enzyme (MTRR A66G) leads to the exchange of A for $G$ in the nucleotide 66 . It also leads to the substitution of Isoleucine by Methionine, which results in a decrease of MTRR affinity by MS (24). Thus, the polymorphic genotype was negatively associated with homocysteinemia, which alters DNA methylation and, consequently, gene expression $(23,25)$.

TS enzyme catalyzes the conversion of deoxyuridine monophosphate (dUMP) into deoxythymidine monophosphate (dTMP), the only de novo source of thymidine for DNA synthesis and repair. TS binds to RNA to repress the translation of its messenger RNA (mRNA) or other proteins and can regulate cell cycle progression (26-28). Moreover, TS expression is an index of cell proliferation and the biological malignancy of cancer (29). The most frequently studied polymorphisms are double or triple $28 \mathrm{bp}$ tandem repeat in 5'-untranslated enhanced region (TSER), and 6 bp deletion/insertion at nucleotide 1494 in TS 3'-untranslated region (TS3'UTR). These two genetic variations may influence the TS gene expression and the stability of its mRNA, respectively (28).

Alterations in the one-carbon metabolism compromise the integrity of genetic material. Such compromise is due to changes in the nucleotide pool and uracil incorporation, which leads to DNA instability. Besides, 
global hypomethylation and site-specific hypermethylation are observed, which lead to the activation of proto-oncogenes and silencing of tumor suppressor genes $(10,30,31)$.

Therefore, the aim of this study was to evaluat the risk of persistence of pre-neoplastic cervical lesions according to genetic polymorphisms involved in one-carbon metabolism.

\section{2) Methods}

\section{1) Study design}

Two hundred and eighty women were selected for this study between October 2016 and September 2018. They all lived in Minas Gerais State and attended the Basic Health Units of Ouro Preto and State Specialized Care Center of Itabirito. To be included in the study, their age should be at least 18 years. We excluded women who had been pregnant within the last six months, had a history of neoplasia, or the presence of cervical atypia in glandular cells.

At the first meeting $\left(T_{1}\right)$, we interviewed them to get sociodemographic and behavioral information. We also collected a cervical sample for cytological analysis, genetic polymorphism evaluation, and HPV detection. After six months of follow-up $\left(\mathrm{T}_{2}\right), 164$ women performed the second cytological analysis. A total of 58 participants were excluded: 50 who presented normal cytology at $T_{1}$ and $T_{2}$, and eight who presented normal cytology at $\mathrm{T}_{1}$ and pre-neoplastic lesion at $\mathrm{T}_{2}$ (Figure 1). We divided the resulting sample group ( $n=106)$ into:

- Remission ( $n=60)$ : presence of pre-neoplastic lesion at $T_{1}$, and normal cytology at $T_{2}$, out of which;

- $0 \%(n=27)$ presented Atypical Squamous Cells of Undetermined Significance (ASC-US) at $\mathrm{T}_{1}$;

- $0 \%(n=21)$ presented Low-Grade Squamous Intraepithelial Lesion (LSIL) at $T_{1}$;

- $0 \%(n=9)$ presented High-Grade Squamous Intraepithelial Lesion (HSIL) at $T_{1}$.

- $0 \%(n=3)$ presented Atypical Squamous Cell - cannot exclude HSIL (ASC-H) at $T_{1}$;

- Persistence $(n=46)$ : presence of pre-neoplastic lesion at $T_{1}$ and $T_{2}$ :

- $7 \%(n=32)$ presented the same cervical lesion at $T_{1}$ and $T_{2}$ :

- ASC-US at $T_{1}$ and $T_{2}(n=8,25.0 \%)$;

- LSIL at $\mathrm{T}_{1}$ and $\mathrm{T}_{2}(\mathrm{n}=9,28.1 \%)$;

- ASC-H at $T_{1}$ and $T_{2}(n=7,21.9 \%)$;

- HSIL at $T_{1}$ and $T_{2}(n=8,25 \%)$.

- $9 \%(n=11)$ presented LSIL at $T_{1}$ and ASC-US at $T_{2}$;

- $4 \%(n=3)$ presented LSIL or ASC-US at T $T_{1}$ and ASC-H at $\mathrm{T}_{2}$. 
We considered the presence of pre-neoplastic lesions when ASC-US, LSIL, HSIL, or ASC-H were detected. Also, as stated before, we only considered the Remission and Persistence groups for statistical analyses, not differentiating the types of cytological abnormalities.

The Research Ethics Committee of the Federal University of Ouro Preto approved this study (CAAE 57187316.7.0000.5150, and CAAE 88479718.0.0000.5150).

\section{2) Sample collection}

Health care professionals obtained cervical samples through the conventional double collection, using Ayre spatulas for the ectocervical sample, and cylindrical brushes for the endocervical sample. After the confection of cervical smear for cytological analysis, the brush was conditioned in Phosphate-Buffered Saline (PBS) pH 7.2 and stored at $-80^{\circ} \mathrm{C}$ for the evaluation of genetic polymorphisms.

\section{3) Cytological analysis}

Cervical smears were stained according to the Papanicolaou method, and samples were evaluated based on cytomorphological criteria described in Bethesda System 2014 for reporting cervical cytological diagnoses (Nayar and Wilbur, 2015). Two cytopathologists evaluated all the samples. In the case of different results, a third professional evaluated the sample. The analyses were performed at the Laboratório de Análises Clínicas (LAPAC) from the Federal University of Ouro Preto.

\section{4) DNA extraction}

DNA was extracted from the cervical samples with illustra blood genomicPrep Mini Spin ${ }^{\text {TM }}$ Kit (GE Healthcare, Chicago, Illinois, USA). The evaluation of the quality and integrity of DNA was performed by amplification of the $\beta$-actin gene (32).

\section{5) HPV detection}

HPV detection was performed by conventional Polymerase Chain Reaction (PCR) with MY09/MY11 primers, as described by Miranda et al. (2013). For positive samples, the HPV genotype was analyzed by Restriction Fragment Length Polymorphism (RFLP) (32). HPV-negative samples were also analyzed by conventional PCR with GP5+/GP6+ primers (33).

2.6) Genetic polymorphisms

MTHFR C677T (rs1801133), MS A2756G (rs1805087), MTRR A66G (rs1801394), and TS3'UTR (rs151264360) polymorphisms were evaluated by PCR-RFLP (14, 34-36). TSER (rs34743033) was evaluated by PCR (37).

Sequences of primers, restriction enzymes, and PCR protocols are shown in Supplementary Tables 1, 2, and 3. Table 1 shows the size of the DNA fragments that characterize the genotypes of the polymorphisms analyzed. 


\section{TABLE 1: Size of DNA fragments for genetic polymorphisms analysis}

\begin{tabular}{lccc}
\hline Genetic polymorphisms & \multicolumn{3}{c}{ Genotypes } \\
& No polymorphic & Heterozygote & Polymorphic \\
\hline MTHFR C677T & $198 \mathrm{bp}$ & $23 \mathrm{bp}, 175 \mathrm{bp}$ and $198 \mathrm{bp}$ & $175 \mathrm{bp}$ and $198 \mathrm{bp}$ \\
MS A2756G & $211 \mathrm{bp}$ & $80 \mathrm{bp}, 131 \mathrm{bp}$ and $211 \mathrm{bp}$ & $80 \mathrm{bp}$ and 131bp \\
MTRR A66G & $22 \mathrm{bp}$ and 44 bp & $22 \mathrm{bp}, 44 \mathrm{bp}$ and $66 \mathrm{bp}$ & $66 \mathrm{bp}$ \\
TS3'UTR & $70 \mathrm{bp}$ and $88 \mathrm{bp}$ & $70 \mathrm{bp}, 88 \mathrm{bp}$ and $152 \mathrm{bp}$ & $152 \mathrm{bp}$ \\
TSER & $220 \mathrm{bp}$ & $220 \mathrm{bp}$ and 248 bp & $248 \mathrm{bp}$ \\
\hline
\end{tabular}

GRS was calculated to evaluate the presence of all polymorphisms simultaneously, as described by Tomita et al. (2013). The presence of heterozygosity received one point; the presence of polymorphic homozygotes received two points. Non-polymorphic homozygotes were not scored (zero) (13). Thus, the higher the GRS, the higher the frequency of genetic polymorphisms.

2.7) Statistical analysis

Data were tabulated by Microsoft Office Excel ${ }^{\mathrm{TM}}$ (Microsoft, Redmond, Washington, USA), and analyzed by Statistical Package for the Social Sciences ${ }^{\mathrm{TM}} 17.0$ (International Business Machines, New York, USA).

To evaluate the frequency of genotypes, we performed descriptive statistics. The allelic frequency was calculated by Genepop software (38). HWE of genotypic frequencies was calculated by the HWE calculator, including analysis for ascertainment bias (39). To compare the groups, we used the Chisquare. Also, we used binary logistic regression to calculate the relative risk (Odds Ratio) with a $95 \%$ confidence interval.

$p$ values $<0.05$ were considered evidence of statistically significant association.

\section{3) Results}

To evaluate the association between genetic polymorphisms in enzymes involved in folate metabolism with cervical carcinogenesis, we analyzed samples of 106 women with remission or 
persistence of cytological abnormalities. We also evaluated sociodemographic and behavioral characteristics such as age, education, use of alcohol, smoking, marital status, information about sexual life, pregnancies, and use of hormonal contraceptives. These characteristics can be considered cofactors of cervical cancer $(5,8,10,40)$.

The mean age of participants was $39.7 \pm 11.4$ years, ranging from 19 to 71 years, and $32.1 \%(n=34)$ were between 35 and 44 years. Most women resided in urban areas $(n=97,91.5 \%)$, had family financial income <US\$250/month ( $n=70,74.5 \%)$, high school education $(n=46,47.9 \%)$, were non-smokers $(n=81$, $84.4 \%)$, and ingested alcoholic beverages $(n=57,59.4 \%)$.

Most of the women reported being married or having a fixed partner $(n=77,80.2 \%)$, having had the first sexual intercourse at the age of 18 years or older $(n=53,56.4 \%)$, and three or more sexual partners $(n=55,57.3 \%)$. Also, most of them did not use hormonal contraceptives $(n=61,63.5 \%)$ and had already been pregnant $(n=81,84.4 \%)$ (Table 2). We observed these characteristics at a similar rate and with no significant association $(\mathrm{p}<0.05)$ among the Remission and Persistence groups (Table 2).

Concerning HPV, the main factor for cervical carcinogenesis (3), $50.9 \%(n=54)$ of the participants were infected. The infection rate was higher in the Persistence group $(n=31,67.4 \%)$ than in the Remission group $(n=23,38.3 \%)(p=0.003)$. We obtained similar results with the analysis of hr-HPV infection alone $(p=0.000)$ (data not shown).

\section{TABLE 2: Sociodemographic and behavioral characteristics}




\begin{tabular}{|c|c|c|c|c|}
\hline Characteristics & $\begin{array}{l}\text { Total } \\
\text { n (\%) }\end{array}$ & $\begin{array}{c}\text { Cytological } \\
\text { Remission } \\
\mathrm{n}(\%)\end{array}$ & $\begin{array}{c}\text { abnormality } \\
\text { Persistence } \\
\text { n (\%) }\end{array}$ & $\mathrm{p}$ \\
\hline \multicolumn{5}{|l|}{ Age (years) } \\
\hline$<25$ & $12(11.3)$ & $7(11.7)$ & $5(10.9)$ & 0.302 \\
\hline $25-34$ & $21(19.8)$ & $9(15.0)$ & $12(26.1)$ & \\
\hline $35-44$ & $34(32.1)$ & $18(30.0)$ & $16(34.8)$ & \\
\hline $45-54$ & $28(26.4)$ & $17(28.3)$ & $11(23.9)$ & \\
\hline$\geq 55$ & $11(10.4)$ & $9(15.0)$ & $2(4.3)$ & \\
\hline \multicolumn{5}{|l|}{ Area } \\
\hline Urban & $97(91.5)$ & $54(90.0)$ & $43(93.5)$ & 0.524 \\
\hline Countryside & $9(8.5)$ & $6(10.0)$ & $3(6.5)$ & \\
\hline \multicolumn{5}{|c|}{ Income per person (US\$/month) ${ }^{1}$} \\
\hline$<250$ & $70(74.5)$ & $40(72.7)$ & $30(76.9)$ & \\
\hline $250-500$ & $21(22.3)$ & $12(21.8)$ & $9(23.1)$ & 0.333 \\
\hline$\geq 500$ & $3(3.2)$ & $3(5.5)$ & 0 & \\
\hline \multicolumn{5}{|l|}{ Education $^{2}$} \\
\hline Elementary school/Illiterate & $44(45.8)$ & $23(41.8)$ & $21(51.2)$ & 0.341 \\
\hline High school & $46(47.9)$ & $27(49.1)$ & $19(46.3)$ & \\
\hline University & $6(6.3)$ & $5(9.1)$ & $1(2.4)$ & \\
\hline \multicolumn{5}{|l|}{ Smoker $^{2}$} \\
\hline No & $81(84.4)$ & $48(87.3)$ & $33(80.5)$ & 0.365 \\
\hline$Y^{a}{ }^{a}$ & $15(15.6)$ & $7(12.7)$ & $8(19.5)$ & \\
\hline \multicolumn{5}{|l|}{ Use of alcoholic beverage ${ }^{2}$} \\
\hline No & $39(40.6)$ & $22(40.0)$ & $17(41.5)$ & 0.885 \\
\hline$Y_{e s}^{a}$ & $57(59.4)$ & $33(60.0)$ & $24(58.5)$ & \\
\hline \multicolumn{5}{|l|}{ Marital status $^{2}$} \\
\hline Married/Fixed Partner & $77(80.2)$ & $40(72.7)$ & $37(90.2)$ & 0.073 \\
\hline
\end{tabular}




\begin{tabular}{|c|c|c|c|c|}
\hline Single & $9(9.4)$ & $8(14.5)$ & $1(2.4)$ & \\
\hline Widow/Divorced & $10(10.4)$ & $7(12.7)$ & $3(7.3)$ & \\
\hline \multicolumn{5}{|c|}{ Age at first vaginal intercourse (years) ${ }^{1}$} \\
\hline$<18$ & $41(43.6)$ & $25(45.5)$ & $16(41.0)$ & \multirow[t]{2}{*}{0.670} \\
\hline$\geq 18$ & $53(56.4)$ & $30(54.5)$ & $23(59.0)$ & \\
\hline \multicolumn{5}{|c|}{ Lifetime sexual partners $^{2}$} \\
\hline 1 & $23(23.9)$ & $13(23.6)$ & $10(24.4)$ & \multirow[t]{3}{*}{0.936} \\
\hline 2 & $18(18.8)$ & $11(20.0)$ & $7(17.1)$ & \\
\hline$\geq 3$ & $55(57.3)$ & $31(56.4)$ & $24(58.5)$ & \\
\hline \multicolumn{5}{|c|}{ Use of hormonal contraceptive ${ }^{2}$} \\
\hline No & $61(63.5)$ & $39(70.9)$ & $22(53.7)$ & \multirow[t]{2}{*}{0.082} \\
\hline Yes & $35(36.5)$ & $16(29.1)$ & $19(46.3)$ & \\
\hline \multicolumn{5}{|l|}{ Pregnancies $^{2}$} \\
\hline 0 & $15(15.6)$ & $9(16.4)$ & $6(14.6)$ & \multirow[t]{5}{*}{0.130} \\
\hline 1 & $19(19.8)$ & $14(25.5)$ & $5(12.2)$ & \\
\hline 2 & $26(27.1)$ & $10(18.2)$ & $16(39.0)$ & \\
\hline 3 & $22(22.9)$ & $12(21.8)$ & $10(24.4)$ & \\
\hline$\geq 4$ & $14(14.6)$ & $10(18.2)$ & $4(9.8)$ & \\
\hline HPV infection & $52(49.1)$ & & & \\
\hline Negative & $54(50.9)$ & $37(61.7)$ & 15 (32.6) & 0.003 \\
\hline Positive & & $23(38.3)$ & $31(67.4)$ & \\
\hline
\end{tabular}

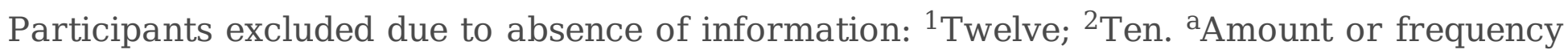
not determined. Remission: presence of pre-neoplastic lesion at $\mathrm{T}_{1}$, and normal cytology at $\mathrm{T}_{2}$; Persistence: pre-neoplastic lesion detected at $\mathrm{T}_{1}$ and $\mathrm{T}_{2}$.

Regarding the genetic polymorphisms evaluated, MTRR A66G genotypic frequencies were $10.4 \%$ $(n=11), 76.4 \%(n=81)$, and $13.2 \%(n=14)$ of $A A, A G$, and $G G$, respectively. The genotypic frequency of 
TSER was $35.8 \%(n=38)$ of $2 R / 2 R, 31.1 \%(n=33)$ of $2 R / 3 R$, and $33.0 \%(n=35)$ of $3 R / 3 R$. However, we could not find the distribution of genotypes of MTRR A66G and TSER of the Remission group under Hardy-Weinberg equilibrium $(p=0.000)$. Thus, these polymorphisms were excluded from further analyses in this study.

MTHFR C677T genotypic frequencies were $50.0 \%(n=53)$ of CC, $45.3 \%(n=48)$ of CT, and $4.7 \%$ $(n=5)$ of TT; the T allelic frequency was $27.4 \%$. We detected the MS A2756G polymorphic genotype in $3.8 \%(n=4)$ of the samples, and $G$ allele in $19.8 \%$. On the other hand, a higher frequency of women presented polymorphic genotype for TS3'UTR genetic variation $(16.0 \%, n=17)$, and the frequency of del allelic was $41.5 \%$ (Table 3 ).

TABLE 3: Frequencies of genetic polymorphisms according Remission or Persistence of pre-neoplastic cervical lesions. 
Genetic

polymorphisms
Cytological abnormality

Total Remission Persistence $(n=60) \quad(n=46)$

\begin{tabular}{|c|c|c|c|c|c|c|}
\hline \multirow{2}{*}{\multicolumn{7}{|c|}{ MTHFR C677T ${ }^{1}$ Genotypen(\%) }} \\
\hline & & & & & & \\
\hline & $\mathrm{CC}$ & $53(50.0)$ & $28(46.7)$ & $25(54.3)$ & \multicolumn{2}{|l|}{1.0} \\
\hline & CT & $48(45.3)$ & $28(46.7)$ & $20(43.5)$ & $0.93(0.40-2.12)$ & 0.856 \\
\hline & TT & $5(2.2)$ & $4(6.6)$ & $1(2.2)$ & $0.25(0.02-2.48)$ & 0.245 \\
\hline \multicolumn{7}{|c|}{ Allele \% } \\
\hline & $C$ & 72.6 & 70.0 & 76.1 & \multicolumn{2}{|l|}{1.0} \\
\hline & $\mathrm{T}$ & 27.4 & 30.0 & 23.9 & $0.71(0.34-2.11)$ & 0.842 \\
\hline
\end{tabular}

\begin{tabular}{|c|c|c|c|c|c|c|}
\hline MS & Genotype $n(\%)$ & & & & & \\
\hline \multirow[t]{6}{*}{$A 2756 G^{2}$} & AA & $69(65.4)$ & $42(70.0)$ & $27(58.7)$ & 1.0 & \\
\hline & $A G$ & 33 (31.1) & $17(28.3)$ & $16(34.8)$ & $1.20(0.50-2.89)$ & 0.690 \\
\hline & GG & $4(3.8)$ & $1(1.7)$ & $3(6.5)$ & $4.99(0.46-54.57)$ & 0.188 \\
\hline & Allele \% & & & & & \\
\hline & A & 80.2 & 83.3 & 76.1 & 1.0 & \\
\hline & G & 19.8 & 16.7 & 23.9 & $1.63(0.59-4.53)$ & 0.349 \\
\hline \multirow[t]{7}{*}{ TS3'UTR $^{3}$} & Genotype $n(\%)$ & & & & & \\
\hline & ins/ins & $34(32.1)$ & $26(43.3)$ & $8(17.4)$ & 1.0 & \\
\hline & ins/del & $55(51.9)$ & $28(46.7)$ & $27(58.7)$ & $3.22(1.19-8.69)$ & 0.021 \\
\hline & $\mathrm{del} / \mathrm{del}$ & $17(16.0)$ & $6(10.0)$ & $11(23.9)$ & $6.50(1.71-24,70)$ & 0.006 \\
\hline & Allele \% & & & & & \\
\hline & ins & 58.5 & 66.7 & 47.8 & 1.0 & \\
\hline & del & 41.5 & 33.3 & 52.2 & $2.28(1.00-5.22)$ & 0.051 \\
\hline \multirow[t]{2}{*}{ GRS n(\%) } & $\leq 2$ & 77 (72.6) & $48(80.0)$ & $29(63.0)$ & 1.00 & \\
\hline & $\geq 3$ & $29(27.4)$ & $12(20.0)$ & $17(37.0)$ & $2.21(0.89-5.48)$ & 0.086 \\
\hline
\end{tabular}

Hardy-Weinberg Equilibrium (HWE): ${ }^{1} p=0.389 ;{ }^{2} p=0.625 ;{ }^{3} p=0.699$. ${ }^{a}$ Adjusted for HPV infection. Remission: presence of pre-neoplastic lesion at $\mathrm{T}_{1}$, and normal cytology at $\mathrm{T}_{2}$; Persistence: pre-neoplastic lesion detected at $\mathrm{T}_{1}$ and $\mathrm{T}_{2}$. 
To evaluate the association between the MTHFR C677T, MS A2756G, and TS3'UTR polymorphisms according to the course of cytological abnormalities, we compared the genotype distribution of the Remission and Persistence groups (Table 3).

There were no differences in the distribution of MTHFR C677T and MS A2756G and the course of cytological abnormalities (Table 3). On the other hand, women with persistent lesions had higher heterozygote and polymorphic genotypic frequencies of TS3'UTR than those from the Remission group. Furthermore, the ins/del and del/del genotypes increased the risk of persistence at least three times [OR (IC95\%): 3.13 (1.21 - 8.12), p=0.019; OR (IC95\%): 5.96 (1.67 - 21.25), p=0.006 - respectively] (Table 3).

To simultaneously evaluate the presence of MTHFR C677T, MS A2756G, and TS3'UTR, we determined the Genetic Risk Score (GRS) (13). A score of $\geq 3$ meant a high number of genetic variants. GRS $\geq 3$ was more frequent in the Persistence group $(n=17,37.0 \%)$ than in the Remission group $(n=12$, $20.0 \%)$. Also, a high number of genetic variants presented higher risk of persistent lesions [OR (IC95\%): 2.21 (0.89 - 5.48), p=0.086] (Table 3). However, when adjusted for TS3'UTR, the risk of persistence according GRS was modified [OR (IC 95\%): 1.26 (0.44-3.61), p=0.669], showing that, between the three polymorphisms analyzed, only TS3'UTR was associated with the course of cytological abnormality.

\section{4) Discussion}

Although persistent hr-HPV infection is the main cause of cervical cancer development, genetic alterations may impact on the risk of this neoplasia. Thus, genetic markers may be useful in the screening of pre-neoplastic and neoplastic cervical lesions, especially in cases of persistent HPV infections or recurrent cytological abnormalities $(7,41)$. Moreover, the conventional methods used for screening cervical cancer cannot differentiate pre-neoplastic cervical lesions that will regress or persist and progress. Therefore, the prognosis of individual pre-neoplastic lesions should be predictable, to select women with a higher risk of persistence and progression, which could decrease the number of unnecessary treatment of lesions (4).

In this study, we evaluated five genetic polymorphisms in enzymes that act on one-carbon metabolism: MTHFR C677T, MS A2756G, MTRR A66G, TSER, and TS3'UTR. However, the distributions of MTRR A66G and TSER were not under Hardy-Weinberg Equilibrium (HWE), which led to their exclusion from further analyses. Other studies with the Brazilian population did not present a genotypic distribution of these polymorphisms under HWE either $(42,43)$.

Many polymorphisms were identified in the TS gene, located on chromosome 18p11.32. One of the most frequently studied polymorphisms is TS3'UTR, related to an increased in vitro degradation of its mRNA, 
which led to a decrease of expression protein (36). The presence of the polymorphic allele (del) of TS3'UTR doubled the risk of persistence of cytological abnormalities. It was probably due to decreased synthesis of thymidylate, catalyzed by the TS enzyme. This enzyme's activity is decreased by TS3'UTR polymorphism, and, as a result, DNA uracil is incorporated. The consequence of that is DNA instability and chromosome damage, crucial for carcinogenesis $(26,36,44)$.

The integration of the HPV genome and the DNA of the host cell is probably one of the decisive steps for oncogenesis. It occurs preferentially in transcriptionally active regions, close to fragile DNA sites, and is observed in most invasive cancers (45). Also, the HPV genome is integrated with chromosomes in some low-grade lesions and in most high-grade lesions $(46,47)$.

On the other hand, although the MTHFR C677T and MS A2756G polymorphisms have already been associated with pre-neoplastic and neoplastic lesions in the uterine cervix, we did not observe any association of these SNPs with the persistence of cytological abnormalities $(11,13)$.

The limitations of this study were the small sample size, the loss of participants during the study, and the short follow-up time. To better understand the role of genetic cofactors on cervical carcinogenesis, it is necessary to carry out more extensive studies, for a more extended period, and with different population groups. Besides, one should also consider different grades of cytological abnormalities separately.

In this study, we only considered the Remission and Persistence groups for statistical analyses due to the small number of samples of each subgroup. Still, analyzing these subgroups separately, there was no significant difference in genotypic or allelic frequencies of the evaluated polymorphisms (data not shown).

Nevertheless, this was the first study to evaluate the link between the risk of persistence of pre-neoplastic cervical lesions and the presence of genetic polymorphisms in enzymes that act on folate metabolism. Some authors have shown an association between the TS3'UTR polymorphism and esophageal, gastric, and breast cancers, although the results were controversial and varied with ethnicity (48-52). However, studies on this polymorphism as a marker of cervical carcinogenesis have shown promising results, and further investigations are needed.

\section{5) Conclusions}

The presence of the TS3'UTR polymorphism increased the risk of cervical abnormalities persistence. Thus, this genetic variant could be a potential marker of cervical carcinogenesis, which would assist the follow-up of women with persistent pre-neoplastic cervical lesions.

\section{6) List Of Abbreviations}

A: Adenine; 
ASC-H: Atypical Squamous Cell - cannot exclude High Grade Squamous Intraepithelial Lesion;

ASC-US: Atypical Squamous Cells of Undetermined Significance;

C: Cytosine;

dTMP: deoxythymidine monophosphate;

dUMP: deoxyuridine monophosphate;

G: Guanine;

GRS: Genetic Risk Score;

HPV: Human Papillomavirus;

hr-HPV: high-risk Human Papillomavirus;

HSIL: High Grade Squamous Intraepithelial Lesion;

HWE: Hardy-Weinberg Equilibrium;

LAPAC: Laboratório de Análises Clínicas;

LSIL: Low Grade Squamous Intraepithelial Lesion;

mRNA: messenger RNA;

MS: Methionine Synthase;

MS A2756G: polymorphism A2756G of Methionine Synthase;

MTHFR: Methylenetetrahydrofolate Reductase;

MTHFR C677T: polymorphism C667T of Methylenetetrahydrofolate Reductase;

MTRR: Methionine Synthase Reductase;

MTRR A66G: polymorphism A66G of Methionine Synthase Reductase;

PBS: Phosphate-Buffered Saline;

PCR: Polymerase Chain Reaction;

RFLP: Restriction Fragment Length Polymorphism;

SNP: Single Nucleotide Polymorphism; 
T: Thymine;

$\mathrm{T}_{1}$ : First meeting;

$\mathrm{T}_{2}$ : Second meeting, after six months of follow-up;

TS: Thymidylate Synthase;

TS3'UTR: 6 bp deletion at nucleotide1494 in TS 3'-untranslated region;

TSER: Double or triple $28 \mathrm{bp}$ tandem repeat in 5'-untranslated enhanced region of Thymidylate Synthase.

\section{7) Declarations}

Ethics approval and consent to participate: Research Ethics Committee of Federal University of Ouro Preto approved this study (CAAE 57187316.7.0000.5150, and CAAE 88479718.0.0000.5150). All women invited and who agreed to participate in this study signed the consent form to participate.

Consent for publication: Not applicable.

Availability of data and materials: The datasets used and/or analyzed during the current study are available from the corresponding author on reasonable request.

Competing interests: There are no compenting interests.

Funding: This work was supported by grants from Pró-Reitoria de Pós-Graduação e Pesquisa PROPP/UFOP (082017066, and 082017013). The funder had no role in the design of the study, collection, analysis, and interpretation of data or in writing the manuscript.

Authors' contributions: NNTS, ACSS, CMC, and AAL analyzed and interpreted the patient data regarding the cytological analyses, HPV infection, and genetic polymorphisms. VMN assisted in selection of participants, and collection of cervical samples. All authors read and approved the final manuscript.

Acknowledgements: To Laboratório de Análises Clínicas (LAPAC) for infrastructure.

\section{8) References}

1. Schiffman M, Wentzensen N. Human papillomavirus infection and the multistage carcinogenesis of cervical cancer. Cancer Epidemiol Biomarkers Prev. 2013;22(4):553-60.

2. Sasagawa T, Takagi H, Makinoda S. Immune responses against human papillomavirus (HPV) infection and evasion of host defense in cervical cancer. J Infect Chemother. 2012;18(6):807-15.

3. zur Hausen H. Papillomaviruses and cancer: from basic studies to clinical application. Nat Rev Cancer. 2002;2(5):342-50. 
4. Koeneman MM, Ovestad IT, Janssen EAM, Ummelen M, Kruitwagen RFPM, Hopman AH, et al. Gain of Chromosomal Region 3q26 as a Prognostic Biomarker for High-Grade Cervical Intraepithelial Neoplasia: Literature Overview and Pilot Study. Pathol Oncol Res. 2018.

5. Steenbergen RD, Snijders PJ, Heideman DA, Meijer CJ. Clinical implications of (epi)genetic changes in HPV-induced cervical precancerous lesions. Nat Rev Cancer. 2014;14(6):395-405.

6. Torres-Poveda K, Bahena-Román M, Delgado-Romero K, Madrid-Marina V. A prospective cohort study to evaluate immunosuppressive cytokines as predictors of viral persistence and progression to premalignant lesion in the cervix in women infected with HR-HPV: study protocol. BMC Infect Dis. 2018;18(1):582.

7. Bahrami A, Hasanzadeh M, Shahidsales S, Farazestanian M, Hassanian SM, Moetamani Ahmadi M, et al. Genetic susceptibility in cervical cancer: From bench to bedside. J Cell Physiol. 2018;233(3):1929-39.

8. Castellsagué X, Muñoz N. Chapter 3: Cofactors in human papillomavirus carcinogenesis-role of parity, oral contraceptives, and tobacco smoking. J Natl Cancer Inst Monogr. 2003(31):20-8.

9. Fang DH, Ji Q, Fan CH, An Q, Li J. Methionine synthase reductase A66G polymorphism and leukemia risk: evidence from published studies. Leuk Lymphoma. 2014;55(8):1910-4.

10. Szalmás A, Kónya J. Epigenetic alterations in cervical carcinogenesis. Semin Cancer Biol. 2009;19(3):144-52.

11. Zhu J, Wu L, Kohlmeier M, Ye F, Cai W. Association between MTHFR C677T, MTHFR A1298C and MS A2756G polymorphisms and risk of cervical intraepithelial neoplasia II/III and cervical cancer: a meta-analysis. Mol Med Rep. 2013;8(3):919-27.

12. Tong SY, Kim MK, Lee JK, Lee JM, Choi SW, Friso S, et al. Common polymorphisms in methylenetetrahydrofolate reductase gene are associated with risks of cervical intraepithelial neoplasia and cervical cancer in women with low serum folate and vitamin B12. Cancer Causes Control. 2011;22(1):63-72.

13. Tomita LY, D'Almeida V, Villa LL, Franco EL, Cardoso MA, Group BS. Polymorphisms in genes involved in folate metabolism modify the association of dietary and circulating folate and vitamin B-6 with cervical neoplasia. J Nutr. 2013;143(12):2007-14.

14. Frosst P, Blom HJ, Milos R, Goyette P, Sheppard CA, Matthews RG, et al. A candidate genetic risk factor for vascular disease: a common mutation in methylenetetrahydrofolate reductase. Nat Genet. 1995;10(1):111-3.

15. Trimmer EE. Methylenetetrahydrofolate reductase: biochemical characterization and medical significance. Curr Pharm Des. 2013;19(14):2574-93.

16. Henao OL, Piyathilake CJ, Waterbor JW, Funkhouser E, Johanning GL, Heimburger DC, et al. Women with polymorphisms of methylenetetrahydrofolate reductase (MTHFR) and methionine synthase (MS) are less likely to have cervical intraepithelial neoplasia (CIN) 2 or 3. Int J Cancer. 2005;113(6):991-7. 
17. Sharp L, Little J. Polymorphisms in genes involved in folate metabolism and colorectal neoplasia: a HuGE review. Am J Epidemiol. 2004;159(5):423-43.

18. Fowler B. The folate cycle and disease in humans. Kidney Int Suppl. 2001;78:S221-9.

19. van der Put NM, van der Molen EF, Kluijtmans LA, Heil SG, Trijbels JM, Eskes TK, et al. Sequence analysis of the coding region of human methionine synthase: relevance to hyperhomocysteinaemia in neural-tube defects and vascular disease. QJM. 1997;90(8):511-7.

20. Chen LH, Liu ML, Hwang HY, Chen LS, Korenberg J, Shane B. Human methionine synthase. cDNA cloning, gene localization, and expression. J Biol Chem. 1997;272(6):3628-34.

21. Paz MF, Avila S, Fraga MF, Pollan M, Capella G, Peinado MA, et al. Germ-line variants in methyl-group metabolism genes and susceptibility to DNA methylation in normal tissues and human primary tumors. Cancer Res. 2002;62(15):4519-24.

22. Weiner AS, Beresina OV, Voronina EN, Voropaeva EN, Boyarskih UA, Pospelova TI, et al. Polymorphisms in folate-metabolizing genes and risk of non-Hodgkin's lymphoma. Leuk Res. 2011;35(4):508-15.

23. Wang P, Li S, Wang M, He J, Xi S. Association of MTRR A66G polymorphism with cancer susceptibility: Evidence from 85 studies. J Cancer. 2017;8(2):266-77.

24. Leclerc D, Wilson A, Dumas R, Gafuik C, Song D, Watkins D, et al. Cloning and mapping of a cDNA for methionine synthase reductase, a flavoprotein defective in patients with homocystinuria. Proc Natl Acad Sci U S A. 1998;95(6):3059-64.

25. Gaughan DJ, Kluijtmans LA, Barbaux S, McMaster D, Young IS, Yarnell JW, et al. The methionine synthase reductase (MTRR) A66G polymorphism is a novel genetic determinant of plasma homocysteine concentrations. Atherosclerosis. 2001;157(2):451-6.

26. Choi SW, Mason JB. Folate and carcinogenesis: an integrated scheme. J Nutr. 2000;130(2):129-32.

27. Voeller D, Rahman L, Zajac-Kaye M. Elevated levels of thymidylate synthase linked to neoplastic transformation of mammalian cells. Cell Cycle. 2004;3(8):1005-7.

28. Zhou JY, Shi R, Yu HL, Zeng Y, Zheng WL, Ma WL. The association between two polymorphisms in the TS gene and risk of cancer: a systematic review and pooled analysis. Int J Cancer. 2012;131(9):2103-16.

29. lida M, Banno K, Yanokura M, Nakamura K, Adachi M, Nogami Y, et al. Candidate biomarkers for cervical cancer treatment: Potential for clinical practice (Review). Mol Clin Oncol. 2014;2(5):647-55.

30. Duthie SJ. Folate and cancer: how DNA damage, repair and methylation impact on colon carcinogenesis. J Inherit Metab Dis. 2011;34(1):101-9.

31. Anderson OS, Sant KE, Dolinoy DC. Nutrition and epigenetics: an interplay of dietary methyl donors, one-carbon metabolism and DNA methylation. J Nutr Biochem. 2012;23(8):853-9.

32. Miranda PM, Silva NN, Pitol BC, Silva ID, Lima-Filho JL, Carvalho RF, et al. Persistence or clearance of human papillomavirus infections in women in Ouro Preto, Brazil. Biomed Res Int. 2013;2013:578276. 
33. Jacobs MV, Snijders PJ, van den Brule AJ, Helmerhorst TJ, Meijer CJ, Walboomers JM. A general primer GP5+/GP6(+)-mediated PCR-enzyme immunoassay method for rapid detection of 14 high-risk and 6 low-risk human papillomavirus genotypes in cervical scrapings. J Clin Microbiol. 1997;35(3):791-5.

34. Shekari M, Sobti RC, Kordi Tamandani DM, Suri V. Impact of methylenetetrahydrofolate reductase (MTHFR) codon (677) and methionine synthase (MS) codon (2756) on risk of cervical carcinogenesis in North Indian population. Arch Gynecol Obstet. 2008;278(6):517-24.

35. Wilson A, Platt R, Wu Q, Leclerc D, Christensen $B$, Yang $H$, et al. A common variant in methionine synthase reductase combined with low cobalamin (vitamin B12) increases risk for spina bifida. Mol Genet Metab. 1999;67(4):317-23.

36. Ulrich CM, Bigler J, Velicer CM, Greene EA, Farin FM, Potter JD. Searching expressed sequence tag databases: discovery and confirmation of a common polymorphism in the thymidylate synthase gene. Cancer Epidemiol Biomarkers Prev. 2000;9(12):1381-5.

37. Villafranca E, Okruzhnov Y, Dominguez MA, García-Foncillas J, Azinovic I, Martínez E, et al. Polymorphisms of the repeated sequences in the enhancer region of the thymidylate synthase gene promoter may predict downstaging after preoperative chemoradiation in rectal cancer. J Clin Oncol. 2001;19(6):1779-86.

38. Rousset F. genepop'007: a complete re-implementation of the genepop software for Windows and Linux. Mol Ecol Resour. 2008;8(1):103-6.

39. Rodriguez S, Gaunt TR, Day IN. Hardy-Weinberg equilibrium testing of biological ascertainment for Mendelian randomization studies. Am J Epidemiol. 2009;169(4):505-14.

40. Fang J, Zhang H, Jin S. Epigenetics and cervical cancer: from pathogenesis to therapy. Tumour Biol. 2014;35(6):5083-93.

41. Cardoso MFS, Castelletti CHM, Lima-Filho JL, Martins DBG, Teixeira JAC. Putative biomarkers for cervical cancer: SNVs, methylation and expression profiles. Mutat Res. 2017;773:161-73.

42. Nogueira Junior JdS, Marson FAdL, Bertuzzo CS. Thymidylate synthase gene (TYMS) polymorphisms in sporadic and hereditary breast cancer. BioMed Central Research Journal; 2012. p. 676-81.

43. Bezerra AM, Sant'Ana TA, Gomes AV, de Lacerda Vidal AK, Muniz MT. Tyms double (2R) and triple repeat (3R) confers risk for human oral squamous cell carcinoma. Mol Biol Rep. 2014;41(12):773742.

44. Mandola MV, Stoehlmacher J, Zhang W, Groshen S, Yu MC, Iqbal S, et al. A 6 bp polymorphism in the thymidylate synthase gene causes message instability and is associated with decreased intratumoral TS mRNA levels. Pharmacogenetics. 2004;14(5):319-27.

45. Peter M, Stransky N, Couturier J, Hupé P, Barillot E, de Cremoux P, et al. Frequent genomic structural alterations at HPV insertion sites in cervical carcinoma. J Pathol. 2010;221(3):320-30.

46. Burd EM. Human papillomavirus and cervical cancer. Clin Microbiol Rev. 2003;16(1):1-17. 
47. de Villiers EM, Fauquet C, Broker TR, Bernard HU, zur Hausen H. Classification of papillomaviruses. Virology. 2004;324(1):17-27.

48. Tang J, Wang PP, Zhuang YY, Chen WJ, Huang FT, Zhang SN. Thymidylate synthase genetic polymorphisms and cancer risk: a meta-analysis of 37 case-control studies. Chin Med $\mathrm{J}$ (Engl). 2012;125(14):2582-8.

49. Wang J, Wang B, Bi J, Di J. The association between two polymorphisms in the TYMS gene and breast cancer risk: a meta-analysis. Breast Cancer Res Treat. 2011;128(1):203-9.

50. Guan X, Liu H, Ju J, Li Y, Li P, Wang LE, et al. Genetic variant rs16430 6bp > 0bp at the microRNAbinding site in TYMS and risk of sporadic breast cancer risk in non-Hispanic white women aged $\leq 55$ years. Mol Carcinog. 2015;54(4):281-90.

51. Gao CM, Takezaki T, Wu JZ, Liu YT, Ding JH, Li SP, et al. Polymorphisms in thymidylate synthase and methylenetetrahydrofolate reductase genes and the susceptibility to esophageal and stomach cancer with smoking. Asian Pac J Cancer Prev. 2004;5(2):133-8.

52. Mo A, Zhao Y, Shi Y, Qian F, Hao Y, Chen J, et al. Association between polymorphisms of thymidylate synthase gene 5'- and 3'-UTR and gastric cancer risk: meta-analysis. Biosci Rep. 2016;36(6).

\section{9) Supplementary Material}

\section{TABLE 1: Sequences of primers, and restrictions enzymes used for analysis of genetic polymorphisms.}

\begin{tabular}{|c|c|c|c|}
\hline $\begin{array}{c}\text { Genetic } \\
\text { polymorphisms }\end{array}$ & Sequences of nucleotides & $\begin{array}{c}\text { Restriction } \\
\text { Enzyme }\end{array}$ & Reference \\
\hline \multirow[t]{2}{*}{ MTHFR C677T } & 5’ TGAAGGAGAAGGTGTCTGCGGGA 3' & Hinfl & (14) \\
\hline & 5’ AGGACGGTGCGGTGAGAGTG 3' & & \\
\hline \multirow[t]{2}{*}{ MS A2756G } & 5' TGTTCCAGACAGTTAGATGAAAATC3' & Haelll & (34) \\
\hline & 5' GATCCAAAGCCTTTTACACTССТСЗ' & & \\
\hline \multirow[t]{2}{*}{ MTRR A66G } & 5'GCAAAGGCCATCGCAGAAGACAT3' & Ndel & (35) \\
\hline & 5'GTGAAGATCTGCAGAAAATCCATGTA3' & & \\
\hline \multirow[t]{2}{*}{ TS3'UTR } & 5'CAAATCTGAGGGAGCTGAGT3' & Dral & (36) \\
\hline & 5'CAGATAAGTGGCAGTACAGA3' & & \\
\hline \multirow[t]{2}{*}{ TSER } & 5'GTGGCTCCTGCGTTTCCCCC3' & $N A^{1}$ & (37) \\
\hline & 5'CCAAGCTTCGCTCCGAGCCGGCCACAGGCATGGCGCGG3' & & \\
\hline
\end{tabular}

${ }^{1} \mathrm{NA}:$ Not applicable. 
TABLE 2: PCR protocol used for analysis of genetic polymorphisms.

\begin{tabular}{|c|c|c|c|c|}
\hline Genetic polymorphisms & Number of cycles & $\begin{array}{c}\text { Temperature } \\
\left({ }^{\circ} \mathrm{C}\right)\end{array}$ & $\begin{array}{c}\text { Time } \\
\text { (minutes) }\end{array}$ & Stage \\
\hline \multirow[t]{5}{*}{ MTFHR C677T } & 1 & 94 & 1 & Denaturation \\
\hline & & 94 & 1 & Denaturation \\
\hline & 35 & 59 & 0.5 & Annealing \\
\hline & & 72 & 0.5 & Extension \\
\hline & 1 & 72 & 5 & Final Extension \\
\hline \multirow[t]{5}{*}{ MS A2756G } & 1 & 95 & 2 & Denaturation \\
\hline & & 95 & 1 & Denaturation \\
\hline & 35 & 48 & 1 & Annealing \\
\hline & & 72 & 1 & Extension \\
\hline & 1 & 72 & 7 & Final Extension \\
\hline \multirow[t]{5}{*}{ MTRR A66G } & 1 & 94 & 4 & Denaturation \\
\hline & & 94 & 0.5 & Denaturation \\
\hline & 35 & 53 & 0.5 & Annealing \\
\hline & & 72 & 0.5 & Extension \\
\hline & 1 & 72 & 5 & Final Extension \\
\hline \multirow[t]{5}{*}{ TSER } & 1 & 94 & 4 & Denaturation \\
\hline & 35 & 94 & 1 & Denaturation \\
\hline & & 60,6 & 1 & Annealing \\
\hline & & 72 & 1 & Extension \\
\hline & 1 & 72 & 7 & Final Extension \\
\hline \multirow[t]{5}{*}{ TS3'UTR } & 1 & 94 & 5 & Denaturation \\
\hline & 30 & 94 & 0.5 & Denaturation \\
\hline & & 53 & 0.75 & Annealing \\
\hline & & 72 & 0.75 & Extension \\
\hline & 1 & 72 & 5 & Final Extension \\
\hline
\end{tabular}


TABLE 3: Reagents for analysis of genetic polymorphisms by PCR

\begin{tabular}{lccccc}
\hline \multicolumn{1}{c}{ Reagents } & MTHFR C677T & MS A2756G & MTRR A66G & TSER & TS3'UTR \\
\hline PCR Master Mix $^{\text {Th}} 1$ & $12.5 \mu \mathrm{l}$ & $12.5 \mu \mathrm{l}$ & $12.5 \mu \mathrm{l}$ & $12.5 \mu \mathrm{l}$ & $12.5 \mu \mathrm{l}$ \\
Primers $^{2}(10 \mathrm{pmol} / \mu \mathrm{l})$ & $0.25 \mu \mathrm{l}$ & $1.0 \mu \mathrm{l}$ & $1.0 \mu \mathrm{l}$ & $1.0 \mu \mathrm{l}$ & $1.0 \mu \mathrm{l}$ \\
DNA $(15 \mathrm{ng} / \mu \mathrm{l})$ & $1.0 \mu \mathrm{l}$ & $1.0 \mu \mathrm{l}$ & $2.5 \mu \mathrm{l}$ & $5.0 \mu \mathrm{l}$ & $2.5 \mu \mathrm{l}$ \\
Water $^{3}$ & $11.0 \mu \mathrm{l}$ & $9.5 \mu \mathrm{l}$ & $8.0 \mu \mathrm{l}$ & $5.5 \mu \mathrm{l}$ & $8.0 \mu \mathrm{l}$ \\
\hline
\end{tabular}

${ }^{1} 0.2 \mathrm{mM}$ each deoxyribonucleotide (dNTP), $1.5 \mathrm{mM} \mathrm{MgCl}_{2}$ and 1.0 unit of Taq DNA (Promega, Madison, Wisconsin, USA); ${ }^{2}$ IDT (Coralville, lowa, USA); ${ }^{3}$ Nuclease Free-Water (Promega, Madison, Wisconsin, USA).

Figures 


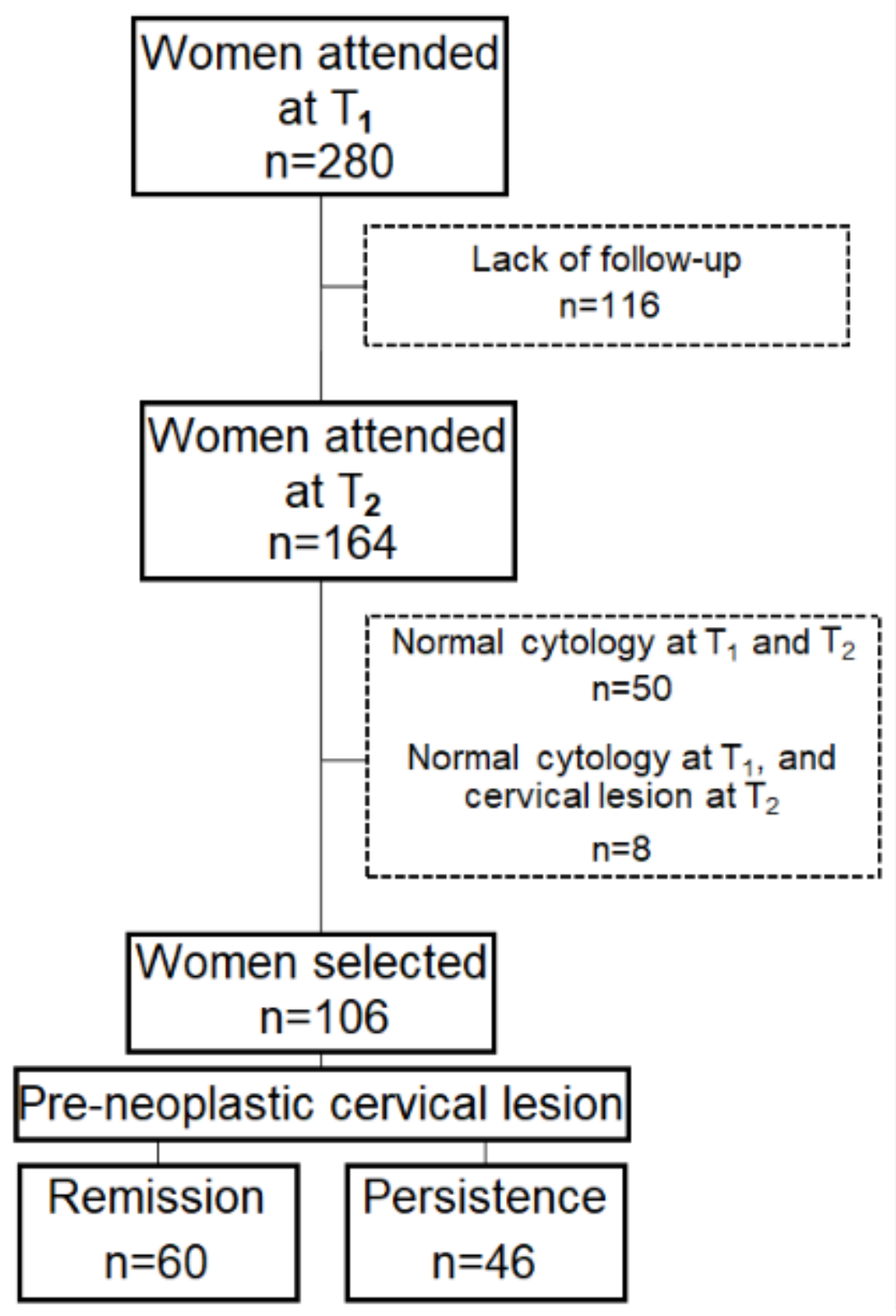

Figure 1

Study flow diagram. T1: First meeting; T2: Second meeting; Remission: Presence of pre-neoplastic cervical lesion at T1, and normal cytology at T2; Persistence: Pre-neoplastic cervical lesion detected at T1 and $\mathrm{T} 2$.

\section{Supplementary Files}

This is a list of supplementary files associated with this preprint. Click to download.

- Supplementarymaterial.docx 